\title{
The digital divide among young people in Brussels: Social and cultural influences on ownership and use of digital technologies
}

\author{
Stefan Mertens and Leen d'Haenens \\ E-Mail: mertens.stefan@scarlet.be; leen.dhaenens@soc.kuleuven.be
}

\begin{abstract}
This article reports on a survey of youth in Brussels $(\mathrm{N}=1,005)$ and their ownership and use of digital technologies, focusing specifically on the social and cultural diversity within this group. Socio-cultural diversity includes differences regarding ethnicity and gender, language and educational attainment, as well as social and economic status. The relationship of these socio-cultural differences with the digital divide in terms of ownership and use is investigated. The data show a persistent ownership divide between socially weaker versus stronger groups accompanied by an emerging socially compensatory function of instrumentally oriented user profiles among the socially weaker groups.
\end{abstract}

Keywords: socio-cultural diversity, digital divide, digital media possession, digital media use, structural and cultural factors

\section{Introduction}

In the 2001 Belgian national census (NIS, 2001) Brussels is revealed as the home of 937,565 inhabitants, of which one-fourth (26.77 percent) are foreign nationals. In reality, however, the number of people with foreign roots is even larger, as many foreigners have "vanished" from the statistics after becoming naturalized Belgian citizens. It is estimated (Van Garsse and Vileyn, 2008) that approximately 57 percent of the Brussels population has foreign origins, with about one-third with non-European heritage.

Brussels, the truly multicultural capital of Belgium and Europe, also aims at taking a leading position in the global information society. Regional political leaders (e. g., Vanhengel, 2006) emphasize the importance of the information society in Brussels, underscoring the necessity of equal access to digital technologies for all citizens. Citizenship in the 
digital era has been called "digital citizenship" (Servaes, 2003; d'Haenens, Koeman and Saeys, 2007; Mossberger, Tolbert and McNeal, 2008), which means that being a full-fledged "citizen" increasingly implies having access to and being able to apply digital technologies. At the same time, digital citizenship risks becoming a monocultural citizenship, one which is only accessible to the ethnic majority. Research (Servaes and Heinderyckx, 2002; Korupp and Szydlik, 2005; d'Haenens et al., 2007) documents that ethnic minorities are one of the high-risk groups for being left out of the information society. The continuation of digital deprivation among ethnic minorities contradicts the political rhetoric on equal access to our modern information society. Although the Brussels government has no explicit policy to enhance the digital access possibilities among ethnic minorities, the cultural diversity in the region invites us to study the digital divide, adopting a comparative perspective between ethnic minorities and the ethnic majority.

Immigrants in Belgium and Brussels come from a variety of different countries. The public debate about immigrants, however, continues to be mainly focused on immigrants from Turkey and Morocco. These two groups both initially came as guest workers following the demand of the Belgian government for more labor power in the 1960s and the early 1970s. Another commonality is that they are Muslims. This article focuses on the particular situation of both these minority groups, comparing them with the broader non-native population in and around Brussels as well as with the native Belgians.

Our investigation addresses the youth in the Brussels school system. This group of young people has been called the "digital generation" (Jenkins, 2004; De Haan and Van 't Hof, 2006). The myth of the digital generation implies that digital technologies have developed a status of such paramount importance among the youth in their everyday lives that there is no longer a digital divide within this generation. Other researchers (Livingstone and Helsper, 2007; Hargittai and Hinant, 2008) point out that age and gender differences as well as social and cultural variables do continue to be important predictors for a persisting digital divide. This article builds on these past findings by testing the importance of the digital divide among youth in the culturally and ethnically diverse region of Brussels.

Our definition of ethnic minority youth requires that at least one parent is of foreign descent. We consider this approach as more "objective" than a definition based on self-reported ethnic identification because, as we experienced during our interviews, asking young people whether they have foreign roots (or not) may provoke various reactions. While some of them may not be willing to see themselves as immigrants because this could imply connotations of being a second-class citizen, others may be 
proud of the country of origin of their ancestors. In other words, we preferred to classify the youth based on an objective criterion instead of on self-reported feelings of adherence.

To contextualize these findings, other socio-demographics such as gender and social class are included in our analysis. As Brussels is officially bilingual, a comparison will be made between members of both language communities (Dutch- and French-speaking). A comparison between the two education types in Belgium will also be included: General education prepares students for further studies, while professional education prepares students for direct entry into the labor market. Finally, four additional measurements, only applicable to the ethnic minority subgroup, will be included in the analysis: nationality, country of birth, and two scales measuring language ability and homeland orientation. The impact of these independent variables on the digital divide is assessed. The latter is operationalized according to what Hargittai (2002) calls the "first level" and the "second level" digital divide. The former refers to having access to digital technologies: This dimension is studied by taking both ownership and use into account. The second level compares user profiles, assuming that more advanced users will develop a more functional rather than an entertainment-oriented user profile (Van Ingen, de Haan and Duimel, 2007).

In the paragraphs to follow, we present a theoretical background, formulate the hypotheses, look further into the composition of the sample and the measurement of the variables, and present the results with regard to access to and use of digital technologies as well as user profiles.

\section{Theoretical background}

In developmental psychology (Valkenburg, Schouten and Peter, 2006) a distinction is made between early (12-14 years) and late adolescence (older than 14 years), whereby early adolescence is considered a period characterized by dramatic hormonal, cognitive, and social changes. During adolescence the basic personality characteristics are consolidated. Our focus is therefore on young people in their late adolescence, whose basic personalities are already consolidated. After age 12 to 13 a socalled "ceiling effect" occurs: "Findings from countries with higher Internet penetration indicate that the increase of access to and frequency of online media stops around the age of $12-13$ years; this is due to a ceiling effect, since from this age on almost all young people use online media" (Hasebrink, Livingstone, Haddon and Olafsson, 2009, p. 18).

Olivier Martin (2007) describes the growing importance of individual ICT (Information and Communication Technologies) use during adolescence as a process of psychological individualization. While growing up, 
young people develop their personal media use patterns, which provide them with an individual social and cultural position in society. Although young people will indeed develop their own personal identity, the classic sociological work of Bourdieu and Passeron (1970) reminds us of the fact that adolescents' position in society is often a reproduction of the position of their parents.

The myth of the digital generation is empirically translated in the socalled "diffusion hypothesis" (described in Peter and Valkenburg, 2006). This hypothesis claims that sociological background variables, responsible for Bourdieu's "reproduction," no longer play a role in explaining the digital divide because of the current widespread importance of new technologies in the lives of young people. The differentiation hypothesis claims that sociological variables continue to be important predictors, including for the digital generation. Earlier research on young people (Peter and Valkenburg, 2006; Livingstone and Helsper, 2007; d'Haenens et al., 2007; Van Ingen et al., 2007; Hargittai and Hinant, 2008) shows that the differentiation hypothesis is more plausible than the diffusion hypothesis, also among young people.

Following Nort, Snyder and Bulfin (2008, p. 898), ICT use can be seen as a form of cultural capital: "Cultural capital [...] consists of academic qualifications, achievements and credentials awarded for people's efforts in education and occupation." Acquiring cultural capital is easier for people whose parents have higher cultural capital - this higher cultural capital often results in a better social and economic position. ICT use can be related to cultural capital and forms as such a part of the possibilities of social mobility among young people. This article assesses whether ICT ownership and use among youth in Brussels are influenced by social and cultural variables. It will therefore be possible to identify whether ICT ownership and use indeed imply a reproduction of the existing social and cultural situation.

Studies of the education system in Belgium (Duquet, Glorieux, Laurijssen and Van Dorsselaer, 2006) show that young people with an immigration background are more likely to have difficulties succeeding in the education system. An important explanation for this phenomenon is suggested by the so-called deprivation theory (described in Duquet et al., 2006; Nicaise, 2007). As youth with foreign backgrounds tend to have weaker social and economic positions, they experience difficulties meeting the demands of the education system. Their lack of cultural capital is, according to the deprivation theory, similar to the lack of cultural capital of Belgian youth from the lower social classes.

According to the "integration theory," the problems young people have with catching up to the requirements of the education system are not only the consequence of social and economic differences, but also of 
specific cultural integration problems. In addition to cultural capital, immigrant youth may have to face the difficulties of cultural adaptation, which can be called the level of "socio-cultural competence." Miglietta and Tartaglia (2009, p. 48) describe this dimension as follows: "Adaptation is also influenced by cultural knowledge, the degree of interaction and identification with the host culture, cultural distance, linguistic competence, and the attitudes and strategies of acculturation [...] Many of these factors taken together make up a sort of general 'sociocultural competence'." We seek to measure the most important aspects of this socio-cultural competence by adding four cultural variables (nationality, country of birth, homeland orientation, and language ability) to the research design.

The predictions related to the diffusion, differentiation, deprivation, and integration theories are tested among young people. While ICT ownership and use is assumed to enhance higher cultural capital, ICT user profiles can however be both related to cultural capital or related to other more entertainment-oriented goals. In their study of opinions of US parents, Schofield Clark, Demont-Heinrich and Webber (2005) report that parents with lower incomes tend to see the potential entertainment character of ICTs as a justification for the limits on use or access of children. Research related to the entertainment or functional orientations of ICT use among socially vulnerable youth shows contradictory results. While a Dutch study by Van Ingen et al. (2007) and a Swiss study by Bonfadelli (2002) find a more entertainment oriented profile among people with lower levels of education, Dutch research by Brouwer (2006), comparative research in the Netherlands and Flanders by d'Haenens et al. (2007), and Norwegian research by Fogt and Sandvik (2008) suggest the possibility that Internet use may be a potentially strong information resource for socially vulnerable youth and, in particular, for youth with an ethnic minority background.

Although research has shown (e. g., Hartmann and Klimmt, 2006) that game culture, a particular dimension of ICT use for entertainment purposes, is more popular among boys, it is often also assumed that boys have a stronger functional orientation towards ICTs. Indeed, the "gender gap" is one of the classical gaps in digital divide research (Van Dijk, 2005). Nevertheless, research on European youth (Hasebrink et al., 2009 , p. 20) shows that the gender gap has shown a narrowing tendency, although some differences still remain important, such as the fact that boys tend to have greater Internet access in their bedrooms than girls.

One particular dimension of the gender gap is described by the integration hypothesis (Duquet et al., 2006, pp. 39-40): This hypothesis also suggests that gender differences are to be expected to be stronger among ethnic minorities, particularly Turkish and Moroccan, because of the 
gender inequality experienced in these cultures. Among these groups it could be assumed that the gender gap closes more slowly. Brouwer (2006) shows, however, that ICT use may have particular emancipatory possibilities for Muslim girls, because the Internet offers them a space where they can freely and anonymously discuss their social and cultural situation.

\section{Hypotheses}

Formulating hypotheses from a classic digital divide approach would imply that socially vulnerable youth are also digitally vulnerable youth. Although we follow this differentiation approach in our hypotheses, we are also aware of studies that point to the potential role of ICT as an information resource among socially vulnerable youth. This classic digital divide formulation leads us to continue to assume the presence of a gender gap, although there is literature reporting a tendency toward closure.

Particularly among youth with immigration backgrounds, we assume that their socially vulnerable position is related to factors rooted in both deprivation and integration problems, again assuming that each cause of social vulnerability translates into digital vulnerability. This also implies the assumption that Muslim girls will have more difficulties catching up with new technologies, although it could also be possible that ICT use for Muslim girls offers specific emancipatory possibilities.

This leads us to the following hypotheses:

H1 Members of ethnic minorities (...)

H2 Francophone youth (...)

$\mathrm{H} 3$ Youth in the professional education system (...)

H4 Youth with lower SES (...)

H5 Non-natives with lower SES and a weaker cultural orientation (i. e. non-Belgian nationality, not born in Belgium, with a stronger homeland orientation and poorer language skills (...)

H6 Boys (...)

H7 Particularly non-native boys (...)
(...) have fewer computers/

Internet connections, use digital technologies less often, own more game consoles, and have a more entertainmentrelated user profile.

\section{(...) have more computers/ \\ Internet connections, use digital technologies more, and have more game consoles.}


Digital vulnerability is a position related to ICT ownership and use with less promising prospects for the development of cultural capital, operationalized as lower ownership levels of computers and Internet connections, a higher degree of game console ownership, and more entertainment oriented user profiles. For boys it will be supposed that their adherence to the game culture goes hand in hand with a higher ownership level and a more functional orientation.

\section{Survey methodology: Composition of the sample and measurements}

In total 1,005 adolescents from 16 different schools took part in the school survey: eight in the Dutch-speaking $(n=485)$ and another eight in the French-speaking part of Brussels $(n=520)$. The importance of ethnic minorities in Brussels can be clearly seen in the distribution of natives and non-natives in the sample. Using the origin of the parents as a criterion, 72.4 percent of the youth had foreign roots (i.e. one or both parents or they themselves were born in a foreign country); 367 youngsters had at least one parent from Turkey or Morocco (36.5\%) and $361(35.9 \%)$ young people had at least one parent from another foreign country; Turkey and Morocco were however by far the most recurrent foreign countries. Cross-tabulation of the variables on the origin of the mother and the origin of the father shows that mixed marriages with parents from two different countries are rather exceptional. Table 1 summarizes the data on origins for the most recurrent origins.

The distribution between girls and boys is close to equal: 50.3 percent boys versus 49.7 percent girls. It was also our intention to obtain an equal distribution between both types of education in the Belgian school system: 56.7 percent of the youth were enrolled in the general education system, while 43.3 percent followed the professional education system. An under-representation of non-native youths was identified in the general education system (63.2 percent of the natives compared to only 54.3 percent of the non-natives). The overrepresentation of non-natives in the professional education system, generally leading to the less lucrative jobs, is a well-documented phenomenon in research (Duquet et al., 2006;

Table 1. Origin of respondents' parents.

\begin{tabular}{lllll}
\hline & Mother $N$ & Mother $\%$ & Father $N$ & Father $\%$ \\
\hline Belgium & 351 & 35.7 & 333 & 34.1 \\
Morocco & 219 & 21.8 & 212 & 21.7 \\
Turkey & 125 & 12.4 & 119 & 11.8 \\
Other & 310 & 30.1 & 341 & 33.9 \\
\hline
\end{tabular}


Jacobs and Rea, 2007). The social and economic status variable (SES) was based upon a measurement scale integrating three elements (occupational status of the parents, father's highest level of education, and mother's highest level of education). A high education score was attributed to the mother or the father when they completed higher studies after secondary education. The measurement scale was dichotomized, resulting in 58.7 percent of the parents with a high SES. The differences between natives and non-natives were noticeable: Among the natives, 86.6 percent had attained a high status, compared to only 49.2 percent of the non-natives. When looking at the sub-sample of Turks and Moroccans in particular, this difference in status becomes even more explicit: Only 24.2 percent of the youth with Turkish or Moroccan roots belong to a more affluent family. There were also many missing values for the questions about socioeconomic status, probably caused by embarrassment to admit low status, although the questionnaire was anonymous.

Let us now briefly discuss the four independent variables measured specifically for the non-native sub-sample. To measure language ability it was asked how often the ethnic minority youth speak their language of origin as well as French or Dutch with their parents, siblings and friends, assuming that languages that are spoken more often are also mastered better: 78 percent of non-natives (and 75.6 percent of the Turks and Moroccans) spoke either Dutch or French more often. Questions about homeland orientation were based on statements by Van Heelsum (1997; see also Gezduci and d'Haenens, 2007) relating to the dimensions of cultural identity. Subjects had to indicate the extent to which they regarded themselves as members of a non-native community and the extent to which they perceived themselves as being regarded and/or treated primarily as members of an ethnic minority community by the majority. The Turks and Moroccans were somewhat more homeland oriented (54.2 percent) than the remaining ethnic minorities (47.5 percent). Finally, it should be mentioned that most ethnic minority youth in our sample were born in Belgium (73.9 percent of the non-natives in general and 87.6 percent of the Turks and Moroccans in particular). Moreover, 80.1 percent of the ethnic minorities have Belgian nationality, compared to 89.8 percent of the Turks and Moroccans.

The dependent variables are all related to measuring the digital divide. Ownership of digital technologies is the dimension that is measured first. We asked the young people whether they had access to a computer and Internet from their own bedrooms or whether they had access to similar equipment in the home. The questions dealing with access to and ownership of computers and Internet connections were complemented with questions on ownership of game consoles. The latter were included to 
determine whether different social and cultural groups have different access and ownership profiles regarding game consoles, which would indicate different affinities with the gaming culture.

In addition to ownership, use of digital technologies is evidently a key aspect. Those who do not personally own a computer or who have no access to an Internet connection from home can perhaps use a computer or an Internet connection elsewhere. The questions about computer and Internet use can determine whether a potential ownership divide also leads to a usage divide. The questions about ownership and use measure the first level digital divide. Questions about the use of several applications were also asked. User profiles are related to the second level digital divide. To test whether users are more entertainment or more functionally oriented, we asked about computer and Internet use to play games or to surf the Internet in search of information on hobbies (indicating an entertainment orientation) or to surf the Internet to search information about school work or to look for employment opportunities or information on political issues (illustrating a more functionally oriented approach).

\section{Results}

\section{Ownership of digital technologies}

Ownership of three digital technologies (computer, Internet, and game platforms) was examined. For each of the investigated platforms we assessed whether the youth had access to these technologies in their home or whether they possessed them personally in their own bedroom or both. Table 2 shows two-by-two comparisons (using cross-tabulations and Chi Square-tests) between the overall sample and the native sample, the Turks and Moroccans and the other non-natives, the youth enrolled in Dutch- or French-speaking education, and so on. Table 3 shows the results of six logistic regression models (Nagelkerke's R-square and betavalues), where all the digital divide variables used were analyzed as predicting (or not) possession or non-possession of specific digital technologies.

Hypothesis 1 presumes that ethnic minorities own fewer digital technologies. This holds true when it comes to Internet ownership, but it is not the case for computer ownership, as our results indicate that the latter remains very high and constant. In other words, the computer seems to be an omnipresent medium.

Higher ownership of game platforms among immigrant youth, both in their parents' homes and in the own bedrooms, also confirms hypothesis 1 . When it comes to computer and Internet in the bedroom, some- 


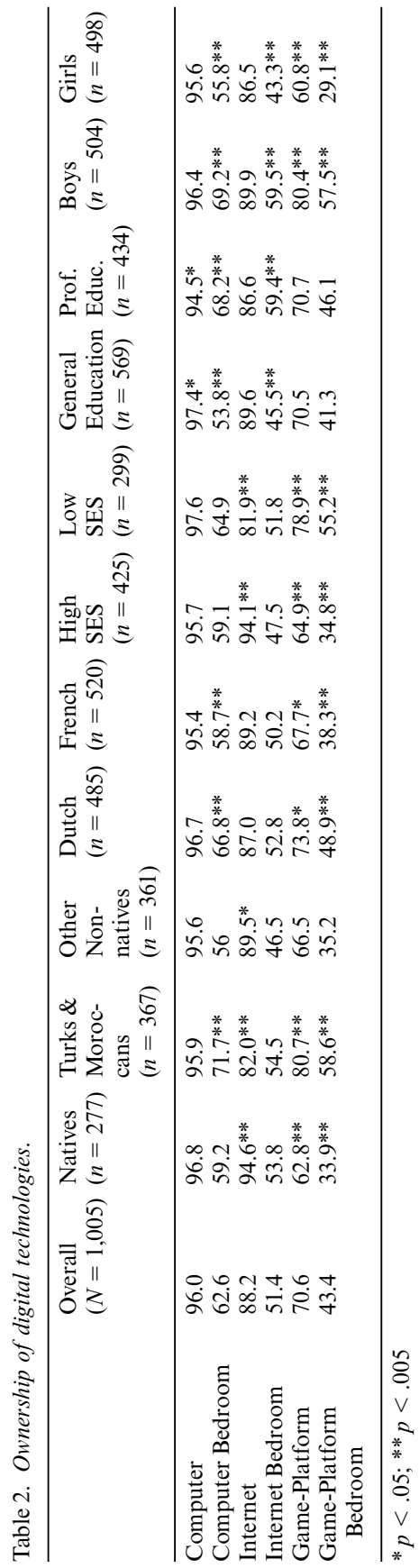


Table 3. Logistic regression analysis of ownership of digital technologies.

\begin{tabular}{llllllll}
\hline & $\mathrm{R}^{2}$ & \multicolumn{2}{l}{ SES } & \multicolumn{2}{l}{ Ethnicity } & Gender & Language \\
& & $\beta$ & $\beta$ & $\beta$ & $\beta$ & $\beta$ \\
\hline Computer & 0.032 & - & - & - & - & - \\
Computer Bedroom & 0.070 & - & - & $0.402^{*}$ & $-0.702^{* *}$ & $0.479^{*}$ \\
Internet & 0.103 & $-1.149^{* *}$ & - & - & - & - \\
Internet Bedroom & 0.066 & - & - & $0.484^{* *}$ & - & $0.681^{* *}$ \\
Game-Platform & 0.128 & $0.461^{*}$ & $0.600^{* *}$ & $1.040^{* *}$ & $-0.562^{* *}$ & - \\
Game-Platform Bedroom & 0.205 & $0.577^{* *}$ & $0.796^{* *}$ & $1.231^{* *}$ & $-0.922^{* *}$ & - \\
\hline
\end{tabular}

$* p<.05 ; * * p<.005$

thing remarkable can be observed: Youth of Turkish and Moroccan origin, assumed to own fewer technologies, have more computers in their bedrooms. As for Internet in the bedroom, non-native youth, irrespective of origin, catch up to their native counterparts in that there is only a significant difference for Internet access in the home and no longer for Internet ownership in the children's bedrooms. Earlier research in Switzerland (Bonfadelli, Bucher and Piga, 2007) shows similar higher degrees of personal media ownership among youth from families with an immigration background.

This compensatory bedroom ownership is not found for Frenchspeaking youth (see hypothesis 2), as Dutch-speaking youth own more game platforms as well as computers in their bedrooms. Nevertheless, there is no statistically significant Internet divide between Dutch and French-speaking youth - in other words, there is no divide due to the omnipresence of the computer.

A computer divide does seem to occur among the youth in the professional education system (see hypothesis 3 ), but this effect in our bivariate analysis disappears when all the variables are introduced together in a logistic regression model. Furthermore, youth in the professional education system do not own more games, which would have made their digital profile weaker, but they do own more computers and have Internet in their bedrooms, which could suggest an overall stronger digital profile.

The digital divides predicted by hypotheses 2 and 3 may not be fully emerging, but the social variable used in hypothesis 4 (social and economic status) clearly has dividing effects. Game possession is large among youth with a low status and their Internet access is lower. Compensatory bedroom access to the Internet and computer ownership in the bedroom does not reach statistical significance. Game platform possession in the bedroom is higher among youth with a low status; then again, game platforms are evidently entertainment-oriented.

Social and economic status proves to be the most powerful social variable. Hypothesis 5 predicts that both cultural and structural factors 
would have an effect on ownership, but when the ethnicity variable and the status variable are both introduced in a logistic regression model along with the other social variables, the effect of ethnicity on Internet possession diminishes to a value of 0.085 .

This indicates that deprivation is a stronger explanatory factor than integration. To further test this finding, logistic regression models were constructed that included status and the four specific variables measured specifically among youth with foreign roots. These models were constructed twice, using both the sample of the Turkish and Moroccan youth and the sample of the other non-natives. Although these models overall showed low $\mathrm{R}^{2}$ values and very few significances, within the Turkish and Moroccan subsamples the status effect on Internet ownership reappeared, again confirming the value of the deprivation hypothesis although the compensatory function of Internet in the bedroom also appeared in this test. Related to the cultural integration hypothesis, only a relationship between language skills and game ownership in the bedroom occurred: Higher language ability accompanies a higher possession of game platforms in the bedroom, both in the subsample of Turks and Moroccans and in the subsample of the other non-natives.

A further research result confirming the integration hypothesis is visible in table 4, which illustrates the ownership differences between boys and girls in the subsamples of the natives, the Turks and Moroccans, and the other natives.

Table 4 shows that hypothesis 6 is only partly confirmed. While girls generally do not have less access to computers and the Internet, digital equipment is less present in their bedrooms. Game platforms are also more often owned by boys, both in their bedroom and in the home of their parents. However, we should add that the Turkish and Moroccan

Table 4. Gender/origin and ownership of digital technologies.

\begin{tabular}{lllllll}
\hline & $\begin{array}{l}\text { Native } \\
\text { boys } \\
(n=152)\end{array}$ & $\begin{array}{l}\text { Native } \\
\text { girls } \\
(n=125)\end{array}$ & $\begin{array}{l}\text { Turkish } \\
\text { and Mo- } \\
\text { roccan } \\
\text { Boys } \\
(n=165)\end{array}$ & $\begin{array}{l}\text { Turkish } \\
\text { and Mo- } \\
\text { roccan } \\
\text { girls } \\
(n=200)\end{array}$ & $\begin{array}{l}\text { Other } \\
\text { Non- } \\
\text { native } \\
\text { boys } \\
(n=187)\end{array}$ & $\begin{array}{l}\text { Other } \\
\text { Non- } \\
\text { native } \\
\text { girls } \\
(n=173)\end{array}$ \\
\hline Computer & 96.7 & 96.8 & 97 & 95 & 95.7 & 95.4 \\
Computer Bedroom & $68.4^{* *}$ & $48^{* *}$ & $77.6^{*}$ & $67^{*}$ & $62.6^{*}$ & $48.6^{*}$ \\
Internet & 95.4 & 93.6 & 84.2 & 80.5 & 90.4 & 88.4 \\
Internet Bedroom & $64.5^{* *}$ & $40.8^{* *}$ & $63.6^{* *}$ & $47.5^{* *}$ & $51.9^{*}$ & $40.5^{*}$ \\
Game-Platform & $74.3^{* *}$ & $40.8^{* *}$ & $87.9^{* *}$ & $75^{* *}$ & $78.6^{* *}$ & $53.2^{* *}$ \\
Game-Platform & $50^{* *}$ & $14.4^{* *}$ & $71.5^{* *}$ & $48^{* *}$ & $51.3^{* *}$ & $17.9^{* *}$ \\
Bedroom & & & & & & \\
\hline
\end{tabular}

$* p<.05 ; * * p<.005$ 
girls are the most digitally emancipated girls, when compared to native girls and girls with another immigration background. This clearly confirms our hypothesis 7 .

\section{Computer and Internet use}

When looking at ownership of digital technologies, one sees that sociological background variables do have an influence on the digital divide. This finding gives more explanatory value to the differentiation hypothesis than to the diffusion hypothesis. Nevertheless, the differentiation hypothesis should be tested more rigorously on the use of digital technologies. Youth who do not have computer or Internet access at home may use computers or the Internet elsewhere (e. g., at the library, in the homes of family or friends, in cyber cafés, or at school), which implies that ownership differences have less impact on actual use. Our evidence does indeed reveal this effect, as the overall computer and Internet use was very high: 98.4 percent use a computer and 96.8 percent use the Internet. In Flanders, the region adjacent to Brussels, Vandoninck and Roe (2008) find that 31.3 percent of the overall population does not use computers. The Eurobarometer survey (European Commission, 2008) reports that 31 percent of households in Belgium do not have a computer. These high percentages of non-use and non-ownership are very much in contrast with the high computer ownership and use percentages among the youth in our survey.

Only one sociological background variable maintains a statistically significant effect on the digital divide usage data. The difference between youth from the ethnic majority and those belonging to an ethnic minority is the most important variable explaining this divide. This difference becomes more explicit when only looking at Turks and Moroccans: While these groups use both computer and Internet significantly less, the general group of ethnic minorities only uses the Internet slightly less than the majority group.

The underlying causes of this phenomenon were investigated. One possible explanation could be hypothesis 6 , which claims that particularly the weaker social and cultural position of girls in Turkish and Moroccan culture implies that they are lagging behind in their use of digital technologies. This effect, predicted by the integration hypothesis, is not found, as no statistically significant gender usage differences could be found in any of the subsamples investigated (majority vs. minority in general, and Turks vs. Moroccans, in particular).

This does not imply that the effects predicted by the integration hypothesis are completely absent. In order to test hypothesis 7 , logistic regression analyses were conducted for the ethnic minority and the Tur- 
kish and Moroccan subsample using the structural variable social-economic status and the four cultural variables as independent variables and computer and Internet use as dependent variables. The results were more favorable for the integration hypothesis compared to the deprivation hypothesis, although only two Beta values reached a significant level within the Turkish and Moroccan subsamples and no significant results were found within the sample of the other ethnic minorities. Lower language ability in Dutch or French, the native languages in Brussels, proved to be related to lower Internet use. This effect illustrates the accumulation of two deficits in the development of cultural capital: language use and Internet use. In addition to this effect related to cultural capital, an effect also emerged related to cultural position. Non-native youth without Belgian citizenship use computers less. This is an effect related to a cultural position, for young people who have not become naturalized can be presumed to be more separated from the Belgian society. This greater cultural distance accompanied a more pronounced separation from the developing information society.

\section{User profiles}

Hypothesis 1 assumed a more entertainment oriented user profile among ethnic minorities in general and among Turks and Moroccans in particular. This assumption proves to be true when we only look at using the Internet to search for information about homework as a criterion. The four other applications under study, on the contrary, identify a more entertainment oriented profile among Belgian native youth, who were predicted to be more functionally oriented. As in the section on ownership of digital technologies, two tables (tables 5 and 6) are shown: a bivariate and a logistic regression analysis.

Although the classical access digital divide proves to be a confirmation or possibly even a reinforcement of traditional socio-demographic divisions such as the difference between the ethnic majority and ethnic minorities, this reinforcing mechanism does not function in the same way when it comes to the second level digital divide. When members of ethnic minorities do possess and/or use the Internet, this use is often more information oriented, attributing social emancipatory possibilities to the Internet. This is a very clear rejection of hypothesis 1 , which presumes that ethnic minorities will have a more entertainment oriented user profile.

The same compensatory effect can be found when other socio-demographic divisions are observed, such as the difference between the youth in the Dutch-speaking education system versus the francophone education system (hypothesis 2), the difference between youth in professional 


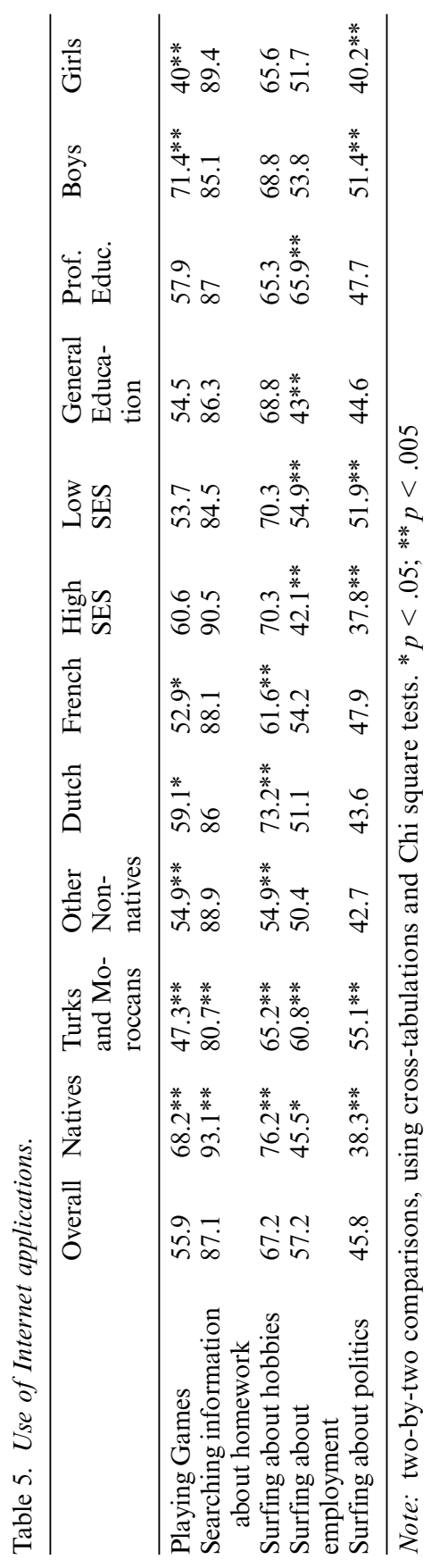


Table 6. Logistic regression on Internet applications.

\begin{tabular}{|c|c|c|c|c|c|c|}
\hline & $\mathrm{R}^{2}$ & $\begin{array}{l}\text { SES } \\
\beta\end{array}$ & $\begin{array}{l}\text { Ethnicity } \\
\beta\end{array}$ & $\begin{array}{l}\text { Gender } \\
\beta\end{array}$ & $\begin{array}{l}\text { Language } \\
\beta\end{array}$ & $\begin{array}{l}\text { Education } \\
\beta\end{array}$ \\
\hline Playing Games & 0.137 & - & $0.475^{*}$ & $1.126^{* *}$ & - & - \\
\hline $\begin{array}{l}\text { Searching information } \\
\text { about homework }\end{array}$ & 0.059 & - & $0.868^{*}$ & $-0.500^{*}$ & $-0.658^{*}$ & - \\
\hline Surfing about hobbies & 0.023 & - & $0.394 *$ & - & $0.359 *$ & - \\
\hline $\begin{array}{l}\text { Surfing about } \\
\text { employment }\end{array}$ & 0.074 & $0.418 *$ & - & - & $0.331^{*}$ & $-0.863^{* *}$ \\
\hline Surfing about politics & 0.035 & $0.521 * *$ & - & - & - & - \\
\hline
\end{tabular}

and general education (hypothesis 3), and the difference between youth from families with lower and higher social and economic status (hypothesis 4). It should be noted that, in terms of these other socio-demographic divisions, the more functional orientation remains limited to one or two statistically significant differences: French-speaking youth play few games and spend less time surfing the Internet about hobbies; youth from a lower social and economic background are more interested in serious topics such as employment and politics; and youth in the professional education also surf more often in search of employment issues. These results allow us to state that the hypotheses 2,3 , and 4 could not be confirmed, because the expected more functional orientation of Dutch-speaking youth (hypothesis 2), youth in professional education (hypothesis 3), and youth from a higher social and economic background (hypothesis 4) could not be found.

The only socio-demographic division that more or less follows the direction predicted by the hypotheses (in particular hypothesis 6) is the gender division, although the results only follow the prediction in a statistically significant way in two of the five tested use dimensions and contradict the prediction in one dimension. On the one hand, boys do play more games (this makes them more entertainment oriented) and show a greater functional orientation in at least one domain considered functional: i.e. surfing the Internet about political topics. On the other hand, girls use the Internet more often to help complete their homework.

Again, we could not find a clear confirmation of the assumption that gender differences among ethnic minority youth in general and Turkish and Moroccan youth in particular are more pronounced (hypothesis 7). While girls from ethnic minorities use the Internet less often for their homework than girls form the ethnic majority do, this difference between non-natives and natives is also observable between boys. The interest of non-native girls, in particular Turkish and Moroccan girls, in using the Internet for information on socially relevant topic such as employment 
and politics is even higher than the interest in these themes among native girls. This evidence on ownership and use contradicts the prediction of the integration hypothesis (i. e. that ethnic minority girls will have more difficulties catching up with the new digital technologies).

To further test the relevance of the integration hypothesis and to evaluate its relative importance in comparison with the deprivation hypothesis (hypothesis 5), we developed logistic regression analyses on the impact of structural in competition with cultural influences on ICT applications within the Turkish and Moroccan subsample as well as within the sample of the other ethnic minority subsample. Although the explanatory value of the independent variables in our model (the $\mathrm{R}^{2}$ values) was generally low, the two statistically significant effects were related to cultural variables. Higher language ability in Dutch and/or French goes hand in hand with using the Internet for information on employment issues in the Turkish and Moroccan subsample, illustrating how lower language ability weakens the position of youth in the emerging information society. Within the sample of the other ethnic minorities, those with a greater homeland orientation show an increased interest using the Internet for political information, which contradicts our earlier expectations. This implies a higher functional orientation among young people with a stronger connection to their country of origin.

\section{Discussion and conclusion}

Comparative European research (Hasebrink et al., 2009, p. 21) shows that there is evidence supporting the hypothesis of a correlation between digital access and SES in almost all European countries. Our research adds evidence to this finding: SES is the variable with the highest explanatory value for the access divide. In addition to SES, ethnicity is also importantly related to the digital divide, because youth with a family history of immigration tend to use computers and the Internet less. Gender, educational attainment, and belonging to the French or Dutchspeaking language community do not have consequences for computer or Internet access and use, although differences in personal ownership (apart from ownership in the home) remain that are related to these variables.

This importance of SES and ethnicity for the access and use divide implies that both social and digital vulnerability are linked. This refers to the classic digital divide reality as far as the first level digital divide is concerned. The results on the second level digital divide are more surprising. Social vulnerability is in some cases connected with more information oriented Internet use. 
Although socially vulnerable youth own more game platforms, they use the Internet less for gaming. This may be explained by the higher cost of Internet games, which may require a broadband connection. Internet gaming may only be a possibility for youth from more affluent social backgrounds; therefore, youth from more vulnerable social backgrounds tend to choose other game platforms for their gaming activities. For similar cost-related reasons socially vulnerable youth may be encouraged not to use the Internet to search for information about hobbies.

Furthermore, our data indicate that socially vulnerable youth are not only less interested in entertainment-oriented applications, they are also more interested in searching for online information about serious matters such as politics and employment, although their use of the Internet for their homework may be a bit weaker than that of youth from stronger social backgrounds.

This tendency toward informative Internet use among youth with foreign roots or a low socio-economic status may be explained as a remedy for a lack of newspaper or magazine subscriptions in their families. Such a finding is suggested by Fogt and Sandviks (2008, p. 112) in their study of media use by ethnic minority youth in Norway: "The families of the ethnic Norwegian pupils subscribed to a newspaper. [...] On the contrary, the multicultural pupils were more active than their ethnic Norwegian counterparts in reading online newspapers both from Norway and from the country with which their family was connected."

Reading online newspapers may give the multicultural youth the status of ICT resource persons in their families (Fogt and Sandvik, 2008, p. 115); ICT use may however also be connected to another process that results in the liberation of the youth from their parents' control. Oliver Martin (2007) describes ICT use as a practice to organize the identity of young people. Communicating via ICT means becoming an individual. He calls this $(2008$, p. 363) the "conquest of autonomy." Because youth with a lower SES and ethnic minority youth may live in families where the parents are less acquainted with ICT, the importance to gain autonomy may be greater for them than for the majority youth or higher SES peers. This hypothesis might also explain the higher ownership levels of ICTs in the children's bedrooms in socially vulnerable families. ICTs are first and foremost a part of their personal space and not that of their parents.

Brouwer (2006) sees the liberating potential of the Internet as a reason why Muslim girls are particularly interested in communicating online. The Internet offers them a space where they can freely discuss their own issues and lives in a virtual world inaccessible to their parents. This explanation would surely help to understand why the lower ICT possibilities for Muslim girls predicted by the integration hypothesis were not 
found. Girls from Turkey and Morocco own indeed fewer ICTs than boys, but this difference is more pronounced between ethnic majority girls and boys. This difference in ICT equipment ownership does not however allow us to draw general conclusions about the relation between girls and boys in contemporary family cultures, as this would require a more comprehensive study.

While the integration hypothesis was not entirely confirmed in our logistic regression on structural and cultural factors, language ability appeared in the results on ownership, use, and user profiles as a factor of importance. Findings on ownership reveal that higher language skills in Dutch and French are accompanied by game platform presence in the bedroom; at the same time, our findings on use and user profiles show language ability as a predictor for Internet use in general and Internet use as a source of information about employment, in other words, an important functional application. This central role of language ability as an important predictor for Internet use for entertainment as well as functional purposes echoes the centrality of linguistic competence as a means of cultural integration found in earlier research (Miglietta and Tartaglia, 2009).

Although our comparison of structural and cultural factors yielded low $\mathrm{R}^{2}$-values, the deprivation hypothesis appeared to confirm the relationship between SES and Internet ownership for this dataset. This brings us back to the strong predicting role of SES. The data on user profiles may suggest that ICT use for cultural capital enhancement is not limited to the socially stronger groups, but it may very well be that at least a higher interest in one functional domain, i. e. surfing the Internet about employment matters, may simply be related to the daily life reality of young people from less advantaged social backgrounds who receive less money from their parents and consequently have to work for their pocket money. To conclude, while the reproduction of the social status of the parents by digital media use is certainly not rejected by this study, there are however some indications of an emerging socially compensatory function of Internet use - as a remedy for lacking resources - among youth from socially more vulnerable backgrounds. Further research is needed to clarify the potential and the strength of this tendency.

\section{References}

Bonfadelli, H. (2002). The internet and knowledge gaps: A theoretical and empirical investigation. European Journal of Communication, 17(1), 65-84.

Bonfadelli, H., Bucher, P., \& Piga, A. (2007). Use of old and new media by ethnic minority youth in Europe with a special emphasis on Switzerland. Communications. The European journal of communication research, 32(2), 141-170. 
Bourdieu, P., \& Passeron, J.C. (1970) La reproduction: éléments pour une théorie $d u$ système d'enseignement. [Reproduction: elements for a theory of the education system.] Paris: Les éditions de Minuit.

Brouwer, L. (2006). Giving Voice to Dutch Moroccan Girls on the Internet, Global Media Journal, 5, Fall 2006, Article No.3, from http://lass.calumet.purdue.edu/cca/ gmj/fa06/gmj_fa06_brouwer.htm

De Haan, J., \& Van't Hof, C. (Eds.) (2006). De Digitale Generatie. [The Digital Generation]. Amsterdam: Boom.

d'Haenens, L., Koeman, J., \& Saeys, F. (2007). Digital citizenship among ethnic minority youths in the Netherlands and Flanders. New Media and Society, 9(2), $278-299$.

Duquet, N., Glorieux, I., Laurijssen, I., and Van Dorsselaer, Y. (2006). Wit krijt schrijft beter. Schoolloopbanen van allochtone jongeren in beeld. [White chalk writes better. School careers of non-native youths portrayed]. Antwerp: Garant.

European Commission (2008). E-Communications Household Survey. Special Eurobarometer 293 / Wave 68.2 (http://ec.europa.eu/public_opinion/archives/eb_special_ en.htm).

Fogt, A., \& Sandvik, M. (2008) "We Represent a Potential, not a Problem": Young People's Media Use in Diaspora. Nordicom Review, 29(1), 111-131.

Gezduci, H., \& d'Haenens, L. (2007). Culture-specific features as determinants of news media use. Communications. The European journal of communication research, 32(2), 193-222.

Hargittai, E. (2002). Second-level digital divide: Differences in people's online skills. First Monday. Peer-reviewed journal on the Internet, 7(4), from http://www. firstmonday.org/Issues/issue7_4/hargittai/

Hargittai, E., \& Hinant, A. (2008). Digital inequality. Differences in young adults' use of the internet, Communication Research, 35(5), 602-621.

Hartmann, T., \& Klimmt, C. (2006). Gender and computer games: Exploring females' dislikes. Journal of Computer-Mediated Communication, 11(4), from http://jcmc.indiana.edu/voll1/issue4/hartmann.html

Hasebrink, U., Livingstone, S., Haddon, L. and Ólafsson, K. (2009) Comparing children's online opportunities and risks across Europe: Cross-national comparisons for EU Kids Online. LSE: London: EU Kids Online (Deliverable D3.2, $2^{\text {nd }}$ edition).

Jacobs, D., \& Rea, A. (2007). Brussels youth: between diversity and adversity. Survey of secondary school students in downtown Brussels. Brussels Studies, 8, from http://www.briobrussel.be/ned/webpage4.asp? WebpageId=53

Jenkins, H. (2004). The myths of growing up online. Alarmist and polarized rhetoric is distorting important new findings about the risks and benefits of children's use of the Internet. Technology Review, from http://www.technologyreview.com/ Biotech/13773/

Korupp, S. E., \& Szydlikk, M. (2005). Causes and trends of the digital divide, European Sociological Review, 21(4), 409-422.

Livingstone, S., \& Helsper, E. (2007). Gradations in digital inclusion: children, young people and the digital divide. New Media and Society, 9(4), 671-696.

Martin, O. (2007) La conquête des outils électroniques de l'individualisation chez les 12-22 ans. [The conquest of electronic media of indivisualisation among 12 to 22 year olds.]. Réseaux, Vol. 2007/5 - n ${ }^{\circ}$ 145-146: 335-366.

Miglietta, A., \& Tartaglia, S. (2009). The Influence of Length of Stay, Linguistic Competence, and Media Exposure in Immigrants' Adaptation. Cross-cultural Research, 43(1), 46-61.

Mossberger, K., Tolbert, C. J., \& McNeal, R. S. (2008). Digital Citizenship. The Internet, society and participation. Cambridge/London: MIT Press. 
Nationaal Instituut voor de Statistiek (2001). Algemene socio-economische enquête. Demografische basisgegevens op 1 oktober 2001. [General Socio-Economic Survey. Demographic basic data on 1 October 2001]. Brussels: NIS.

Nicaise, I. (2007). Education and Migration: Policies and practices for integration and social inclusion. from http://www.nesse.fr/nesse/nesse_top/tasks/network-symposia/ files/seminar4

North, S., Snyder, I., \& Bulfin, S. (2008) Digital tastes: Social class and young people's technology use. Information, Communication and Society, 11 (7), 895-911.

Peter, J., \& Valkenburg, P. M. (2006). Adolescents' internet use: Testing the 'disappearing digital divide' versus the 'emerging digital differentiation' approach'. Poetics, 34, 293-305.

Servaes, J., \& Heinderyckx, F. (2002). The 'new' ICTs environment in Europe: Closing or widening the gaps?. Telematics and Informatics, 19(2), 91-116.

Servaes, J. (2003). Digital citizenship and information inequalities: challenges for the future. In J. Servaes (Ed.), The European Information Society: A reality check (pp. 231-238). Bristol: ECCR Book Series Intellect.

Schofield Clark, L., Demont-Heinrich, C., \& Webber, S. (2005). Parents, ICTs and Children's Prospects for Success: Interviews along the Digital "Access Rainbow". Critical Studies in Media Communication, 22(5), 409-426.

Van Dijk, J. (2005) The Deepening Divide. Inequality in the Information Society. London/Thousand Oaks/New Delhi: Sage.

Vandoninck, S., \& Roe, K. (2008). The digital divide in Flanders: Disappearance or persistence?. Communications. The European Journal of Communication Research, 33(2), 247-255.

Vanhengel, G. (2006). Brussels E-government neusje van de zalm. [E-government in Brussels is a top achievement], from http://www.vanhengel.info/nl/engine/print. php?id=2006111001

Van Garsse, S., \& Vileyn, D (2008). Brussel over 25 jaar: de Brusselaar van de toekomst. [Brussels in 25 years: The Brussels citizen of the future]. Brusselnieuws, from http://www.brusselnieuws.be/artikels/stadsleven/brussel-over-25-jaar-sociolooghertogen-over-de-brusselaar

Van Heelsum, A. J. (1997). De etnisch-culturele positie van de tweede generatie Surinamers. [The ethnic cultural position of Second Generation Surinamese]. Amsterdam: Het Spinhuis.

Van Ingen, E., de Haan, J., \& Duimel, M. (2007). Achterstand en afstand. Digitale vaardigheden van lager opgeleiden, ouderen, allochtonen en inactieven. [Arrears and distance. Digital skills of lower educated people, older people, non-natives and inactive people]. The Hague: Social and Cultural Planning Office of the Netherlands.

Valkenburg, P. M., Schouten, A., \& Peter, J. (2006). Jongeren en hun identiteitsexperimenten op internet [Young people and their identity experiments on the Internet]. In J. De Haan \& C. Van 't Hof (Eds.), De Digitale Generatie. [The Digital Generation]. Amsterdam: Boom. 
Copyright of Communications: The European Journal of Communication Research is the property of De Gruyter and its content may not be copied or emailed to multiple sites or posted to a listserv without the copyright holder's express written permission. However, users may print, download, or email articles for individual use. 